\title{
RHINOLOGY
}

\section{Effects of liposomal nasal spray with vitamins A and $E$ on allergic rhinitis}

\author{
Effetti dell'applicazione di spray liposomiale con vitamine A ed E nelle riniti allergiche \\ Maria Lauriello', Gian Piero di Marco², Stefano Necozione ${ }^{3}$, Cinzia Tucci ${ }^{4}$, Marina Pasqua ${ }^{4}$, Giulia Rizzo' ${ }^{5}$, Alberto Eibenstein ${ }^{1}$ \\ ${ }^{1}$ Department of Biotechnological and Applied Clinical Sciences, University of L'Aquila, Italy; ${ }^{2}$ Department of Otolaryngology, San \\ Salvatore Hospital, L'Aquila, Italy; ${ }^{3}$ Department of Life, Health and Environmental Sciences, University of L'Aquila, Italy; ${ }^{4}$ Speciality \\ School of ENT, University of Tor Vergata, Roma, Italy; ${ }^{5}$ University of L'Aquila, Italy
}

\begin{abstract}
SUMMARY
The aim of this study was to investigate the relationship between nasal obstruction and nasal cytology in patients with allergic rhinitis (AR) treated with a liposomal based nasal spray containing vitamins $\mathrm{A}$ and $\mathrm{E}$. This is a prospective double-blind, controlled study. A total of 106 patients with $A R$, who rejected anti-allergic therapy, were randomly divided into two groups: $G$ (study group, $\mathrm{n}=53$ ) received liposomal nasal spray and $\mathrm{C}$ (control group, $\mathrm{n}=53$ ) received $0.9 \%$ sodium chloride solution nasal spray. Both nasal sprays were applied two times a day, in the morning and at night, in both nasal cavities. The study lasted for 30 days. The first ENT evaluation was performed the first day (T0) and the second evaluation was performed at the end of the study (T1). Symptoms (SNOT-22 test with VAS) and signs (nasal cytology) of both groups were recorded at T0 and T1. Liposomal nasal spray was effective in improving both nasal symptoms and cytology in patients suffering from perennial AR. Treatment with liposomal nasal spray with vitamins A and $E$ was followed by a significant improvement of VAS scale $(\mathrm{p}<0.0001)$, a significant decrease in SNOT-22 $(\mathrm{p}<0.0001)$ and a significant decrease in inflammatory cell count $(\mathrm{p}<0.0001)$. In conclusion, our study provides evidence that liposomal nasal spray improves the nasal symptoms of AR. The patients were compliant to this therapy because of limited side effects. The reduction in inflammatory cells count was remarkable and confirmed the close association between eosinophil infiltration and nasal airflow impairment. These results may have implications for clinical practice.
\end{abstract}

KEY WORDS: allergic rhinitis, liposomal nasal spray, vitamins A and E, nasal cytology, VAS, SNOT-22

\section{RIASSUNTO}

Scopo del nostro studio è stato indagare la relazione tra ostruzione nasale e citologia nasale in pazienti con rinite allergica trattati con spray nasale liposomiale con vitamine A ed E. Lo studio è prospettico, controllato in doppio cieco. I 106 pazienti affetti da rinite allergica, che hanno rifiutato la terapia anti-allergica, ammessi nello studio sono stati assegnati a uno dei due gruppi: G (gruppo di studio, $n=53$ ) che ha assunto uno spray nasale liposomiale con vitamine A ed E e C (gruppo controllo, $n=53$ ) che ha assunto uno spray di soluzione salina $(\mathrm{NaCl}) 0,9 \%$. Entrambi gli spray nasali sono stati assunti mattina e sera per 30 giorni. La prima visita è stata effettuata al tempo zero (T0) e la seconda visita al termine dello studio (T1). In entrambe le visite sono stati valutati i segni (citologia nasale) e i sintomi (SNOT-22 e VAS) della rinite allergica. Lo spray nasale liposomiale con vitamine A ed E è risultato efficace nel migliorare la sintomatologia nasale e nel ridurre la conta cellulare in pazienti affetti da rinite allergica. Nel nostro studio abbiamo evidenziato un miglioramento significativo della scala VAS ( $p<0,0001)$, un'importante riduzione del punteggio del test SNOT-22 $(p<0,0001)$ e una rilevante riduzione della conta delle cellule infiammatorie della mucosa nasale, soprattutto neutrofili ed eosinofili $(p<0,0001)$. Alla luce dei risultati rilevati è possibile affermare che lo spray nasale liposomiale si è dimostrato in grado di migliorare i sintomi della rinite allergica. I pazienti hanno manifestato un'ottima compliance al trattamento proposto per la percezione di un favorevole rapporto tra efficacia e scarsi effetti collaterali. La riduzione della conta cellulare infiammatoria è risultata rilevante, confermando la stretta associazione tra infiltrazione eosinofila e ostruzione nasale. Questi risultati potrebbero avere implicazioni per la pratica clinica.

PAROLE CHIAVE: rinite allergica, spray nasale liposomiale, vitamina A ed E, citologia nasale, VAS, SNOT-22
Received: June 9, 2019

Accepted: October 27, 2019

Correspondence

Maria Lauriello

piazzale Salvatore Tommasi 1, 67100 Coppito,

L'Aquila, Italy

E-mail: lauriellomaria@gmail.com

Funding

None.

Conflict of interest

The Authors declare no conflict of interest.

How to cite this article: Lauriello M, di Marco GP, Necozione $\mathrm{S}$, et al. Effects of liposomal nasal spray with vitamins $\mathrm{A}$ and $\mathrm{E}$ on allergic rhinitis. Acta Otorhinolaryngol Ital 2020;40:217-223. https://doi. org/10.14639/0392-100X-N0357

() Società Italiana di Otorinolaringoiatria e Chirurgia Cervico-Facciale

\section{(c) (1) $\circledast$}

This is an open access article distributed in accordance with the CC-BY-NC-ND (Creative Commons Attribution-NonCommercial-NoDerivatives 4.0 International) license. The article can be used by giving appropriate credit and mentioning the license, but only for non-commercial purposes and only in the original version. For further information: https:// creativecommons.org/licenses/by-nc-nd/4.0/deed.en 


\section{Introduction}

Allergic rhinitis (AR) is a serious public health problem worldwide and one of the most common chronic diseases that affects the daily life of patients with severe symptoms and major disabilities. It is a common disorder that affects up to $40 \%$ of the population of all ages ${ }^{1}$.

Its high and still increasing prevalence, socio-economic burden, frequent association with asthma and significant impairment of quality of life (QoL) make it a disease of substantial importance ${ }^{2}$. Treatment options for allergic rhinitis include allergen avoidance, pharmacological therapy and immunotherapy. Pharmacological therapies include intranasal corticosteroids, anti-leukotrienes and antihistamines: the latter is the most common medication, but is burdened by side effects which often lead to a rejection of the therapy ${ }^{3}$.

The aim of this study was to investigate the relationship between nasal symptoms, mostly nasal obstruction, and nasal cytology in patients with AR treated with a liposomal based nasal spray containing vitamins $\mathrm{A}$ and $\mathrm{E}$. These patients had rejected any other anti-allergic therapy.

The rationale for the use of a liposomal nasal spray is that liposomes support the cleansing, lubrification and hydration of nasal mucosa. Moreover, the rationale for the use of vitamins $\mathrm{A}$ and $\mathrm{E}$ is based on the role of vitamin $\mathrm{A}$ in the immune response and the role of vitamin $\mathrm{E}$ as an antioxidant.

\section{Materials and methods}

\section{Patients}

106 patients (50 males and 56 females, 18 years old or older) with symptoms of allergic rhinitis and positive RAST (radioallergosorbent test) and skin prick test to common perennial allergens: Felis domesticus, Canis familiarus, Dermatophagoides spp., Alternarian alternate, Aspergillus fumigatus were studied. These patients had rejected antiallergic therapy for several reasons, mainly side effects such as drowsiness, dizziness and dry mouth.

Exclusion criteria were the presence of airway infection, sinusitis, tumour of sinuses, adenoidal hypertrophy, previous nasal surgery, nasal fracture in the previous three months, untreated asthma, sarcoidosis, Wegener's granulomatosis, previous head and neck irradiation, smokers and subjects younger than 18 years of age. The ethics committee of San Salvatore Hospital approved the study and all patients enrolled gave their written informed consent (ID of the protocol: 29/2017.18).

\section{Study design}

This was a prospective, double-blind, randomised, controlled study carried out at the Department of
Otorhinolaryngology of San Salvatore Hospital in L'Aquila, Italy, between February 2017 and August 2018. The study lasted for 30 days.

Patients were randomly divided into two groups: $\mathrm{G}$ (study group, $\mathrm{n}=53$ ) and $\mathrm{C}$ (control group, $\mathrm{n}=53$ ). Group $\mathrm{G}$ received a commercially available liposomal $[1.000 \% \mathrm{p} / \mathrm{p}$ $(100 \mathrm{~g})]$ vitamin A $[0,058 \% \mathrm{p} / \mathrm{p}(100 \mathrm{~g})]$ and vitamin E $[0.018 \% \mathrm{p} / \mathrm{p}(100 \mathrm{~g})]$ nasal spray. Other components of the nasal spray are hydrogenated phospholipids, monobasic and bibasic phosphate sodium, $\mathrm{N}$-hydroxymethylglycinate, EDTA (ethylenediaminetetraacetic acid), sodium chloride and purified water. The control group received $0.9 \%$ sodium chloride nasal spray. Both nasal sprays were applied two times a day, in the morning and at night, in both nasal cavities, for 30 days.

A detailed clinical history and a complete ENT physical examination, including nasal endoscopy, was obtained for each patient at first evaluation (T0), before using the nasal spray, and at the second visit (T1) performed at the end of the study, after 30 days of nasal spray usage. Symptoms in both groups were evaluated at T0 and T1 by Sinonasal Outcome Test-22 (SNOT-22) and by a visual analogue scale (VAS); nasal inflammation was evaluated by nasal cytology.

All subjects had to answer an examiner-guided questionnaire, the Italian-SNOT-22 ${ }^{4}$, about their clinical history and nasal symptoms which have a profound influence on the rhinoQoL in people suffering from persistent allergic rhinitis that is closely related to chronic rhinosinusitis ${ }^{5}$. It is a simple and fast questionnaire structurally composed of 22 rhinitisrelated items that evaluate the severity of complaints at first visit. All items are scored from 0 (= no problem) to 5 (= problem as bad as it can be). The sum of each item results in a maximum score of 110 . High score indicates a poor outcome. The items composing the SNOT-22 can be divided into two categories: 12 questions about physical symptoms which cover rhinologic symptoms as well as ear and facial symptoms, and 10 questions about health and QoL which cover sleep function and psychological issues ${ }^{6}$. The VAS scale is an instrument widely used in the rhinology: it is a simple and quantitative method that can be used for quantitative evaluation of severity of allergic rhinitis, according to ARIA ${ }^{7}$. It represents a $10 \mathrm{~cm}$ horizontal scale from 0 to 10: patients are instructed to indicate the point on the line that best corresponds to their status about nasal obstruction. $(0=$ no nasal obstruction, $10=$ complete nasal obstruction) ${ }^{8}$.

Cytology was performed by analysing nasal scrapings obtained from the mucosal surface of the inferior turbinate and samples were stained using haematoxylin and eosin. By using a microscope, inflammatory cell count was done, 
including eosinophils, neutrophils and mast cells ${ }^{9}$. The cytology score was obtained using the high-power field method.

\section{Statistical analysis}

The statistical software package used to analyse data was SAS (Statistical Analysis System). The discrete variables (sex, recent or chronic obstruction, smoking, previous surgery, snoring, sinusitis, polyps, injuries, allergy, nasal septum deviation, turbinate hypertrophy) were analysed with chi-Square or Fisher's exact tests as appropriate.

The normality of continuous variables (age, cytology, VAS, SNOT-22 test) were analysed with the Shapiro Wilk-Test. In consideration of non-normality of distributions, Wilcoxon rank-sum test was used or the variables were transformed logarithmically as appropriate.

Analysis of variance for repeated measures was used to test differences in the variations in the time of the variables between the two groups. The presence of a significant interaction time* groups demonstrates a difference between groups. Spearman nonparametric correlation was used to evaluate correlations between differences in the variations in the time of the variables. Finally, the relation between two variables (cytology and VAS, SNOT-22 test and VAS) was presented in a scatter diagram with a regression line.

\section{Results}

Regarding demographic data, no significant differences between groups in the baseline data of age or gender distribution were noted (Tab. I).

The continuous variables (age, cytology, VAS, SNOT-22 test) were identified by mean, standard deviation and p-value for each group at T0 and T1 (Tab. II).
VAS

At T0, the VAS score was almost the same in the two groups $(6.57 \pm 1.68$ for $\mathrm{G}$ and $6.47 \pm 1.88$ for $\mathrm{C} ; \mathrm{p}=0.785)$. At $\mathrm{T} 1$, subjects in group $\mathrm{G}$ had less severe nasal obstruction, while the comparison between $\mathrm{T} 0$ and $\mathrm{T} 1$ was not significant in group $\mathrm{C}(3.75 \pm 1.41$ for $\mathrm{G}$ and $6.51 \pm 2.00$ for $\mathrm{C} ; \mathrm{p}<0.0001)$ (Fig. 1A). Allergic rhinitis can be divided into three groups according to the VAS score: mild (0-3), moderate (3.1-7) and severe (7.1-10). Before treatment, both groups had a moderate VAS score. After treatment, $\mathrm{G}$ became a class among mild and moderate instead $\mathrm{C}$ remained into the same class (moderate). The Group x Factor interaction detected a significant difference of the variations in the VAS score at $\mathrm{T} 0$ and $\mathrm{T} 1$ between groups $(\mathrm{p}<0.001)$.

\section{Cytology}

At T0, significant differences in cytology values were seen between groups, e.g. G had a higher cell count, including eosinophils, mast cells and, above all, neutrophils, than $\mathrm{C}(10.21 \pm 7.02$ for $\mathrm{G}$ and $8.11 \pm 1.69$ for $\mathrm{C} ; \mathrm{p}<0.001)$ (Fig. 2). At T1, subjects in $\mathrm{G}$ had a significant decrease in cell count until values lower than $\mathrm{C}$; otherwise, no significant differences between the two measurements could be found in $\mathrm{C}(5.57 \pm 2.22$ for $\mathrm{G}$ and $8.70 \pm 3.45$ for C; p < 0.0001) (Fig. 1B).

The Group x Factor interaction detected a significant difference of the variations at $\mathrm{T} 0$ and $\mathrm{T} 1$ between groups $(\mathrm{p}<0.001)$. A significant difference $(\mathrm{p}<0.0001)$ in cytology values at $\mathrm{T} 0$ and $\mathrm{T} 1$ was found in G: only 4 subjects had a higher cytology score after treatment, while 47 patients decreased their cytology score and 2 had the same score; the large sample test statistic $\mathrm{Z}$ was 5.6147. No significant differences $(p=0.1894)$ in cytology at $\mathrm{T} 0$ and $\mathrm{T} 1$ were

Table I. Demographic data.

\begin{tabular}{lccc} 
Demographic data & $\begin{array}{c}\text { Study group (G) } \\
\mathbf{n}=\mathbf{5 3}\end{array}$ & $\begin{array}{c}\text { Control group (C) } \\
\mathbf{n}=\mathbf{5 3}\end{array}$ & P-value \\
& $24 / 29(22.64 / 27.36)$ & $26 / 27(24.53 / 25.47)$ & $0.697^{\mathrm{a}}$ \\
Male/female, $\boldsymbol{n}(\%)$ & $39.66 \pm 15.20$ & $42.21 \pm 12.35$ & $0.238^{\mathrm{b}}$ \\
\hline Age, mean (SD) & & & \\
\hline
\end{tabular}

${ }^{a}$ Chi-Square test; ${ }^{b}$ Wilcoxon rank sum test.

Table II. Continuous variables.

\begin{tabular}{|c|c|c|c|c|c|}
\hline Variable & & $\mathrm{N}$ & $\begin{array}{l}\text { Study group }(G) \\
\text { mean }( \pm S D)\end{array}$ & $\begin{array}{c}\text { Control group }(C) \\
\text { mean }( \pm S D)\end{array}$ & $P^{*}$ \\
\hline \multirow[t]{2}{*}{ Cyto } & TO & 53 & $8.11 \pm 1.69$ & $10.21 \pm 7.02$ & \multirow{2}{*}{$<0.001$} \\
\hline & T1 & 53 & $8.70 \pm 3.45$ & $5.57 \pm 2.22$ & \\
\hline \multirow[t]{2}{*}{ VAS } & TO & 53 & $6.47 \pm 1.88$ & $6.57 \pm 1.68$ & \multirow{2}{*}{$<0.001$} \\
\hline & $\mathrm{T} 1$ & 53 & $6.51 \pm 2.00$ & $3.75 \pm 1.41$ & \\
\hline \multirow[t]{2}{*}{ SNOT } & T0 & 53 & $44.08 \pm 17.49$ & $49.70 \pm 12.88$ & \multirow{2}{*}{$<0.001$} \\
\hline & $\mathrm{T} 1$ & 53 & $43.81 \pm 17.16$ & $34.32 \pm 12.79$ & \\
\hline
\end{tabular}

*:ANOVA for repeated measures time groups interactions. 


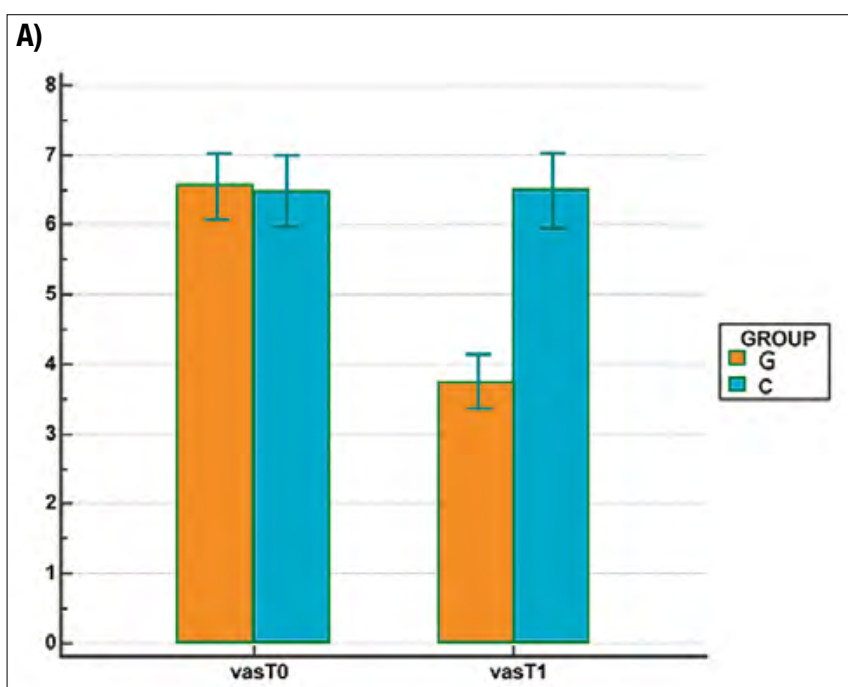

B)

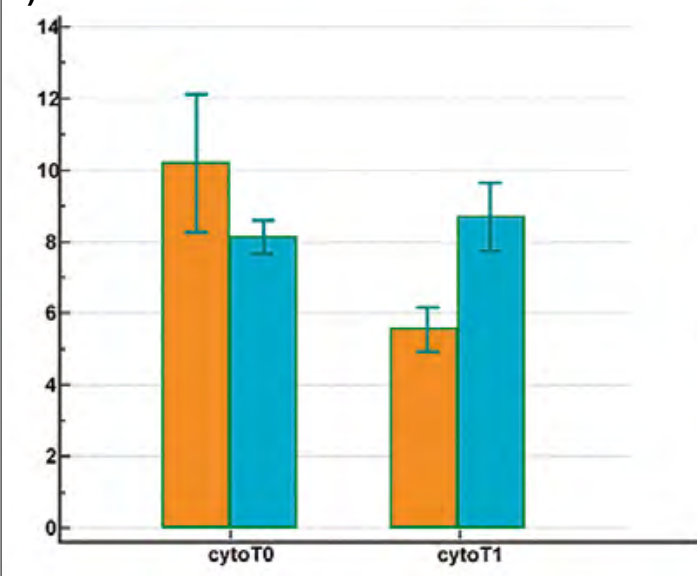

C)

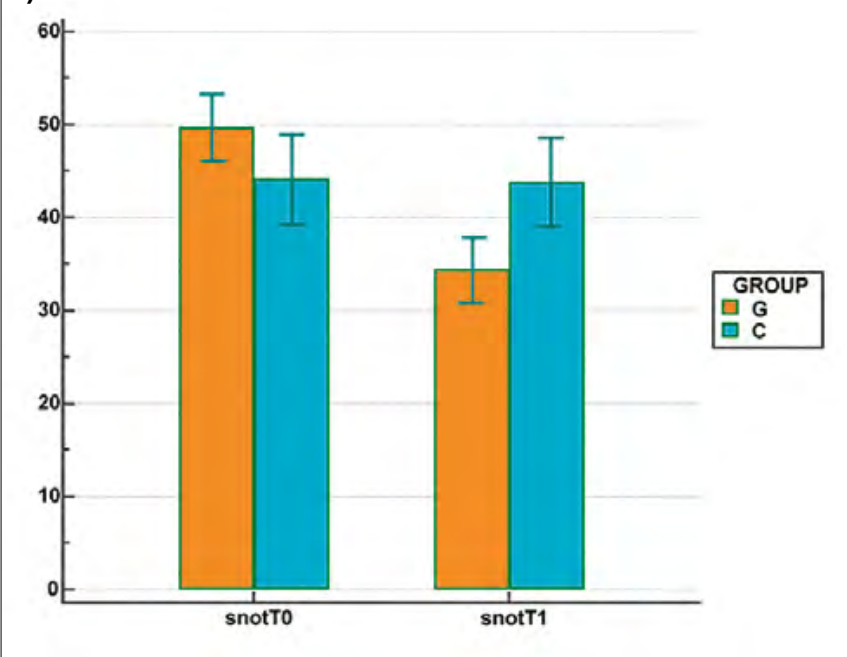

Figure 1. (A) VAS TO/T1 in the treated group (G) vs no treatment (C); (B) Cyto TO/T1 in treated group (G) vs no treatment (C); (C) SNOT TO/T1 in the treated group (G) vs no treatment (C).
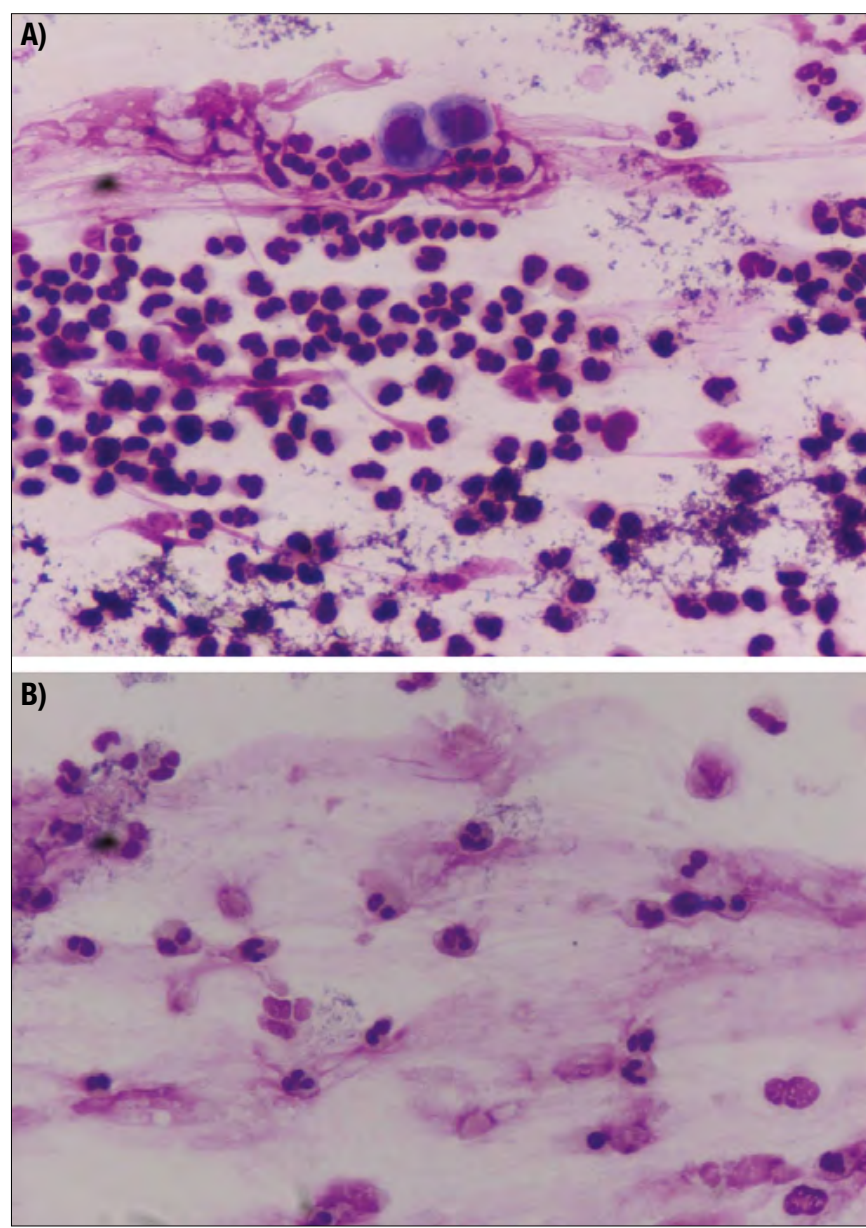

Figure 2. Neutrophils in the nasal scraping in the treated group before $(\mathbf{A})$; and after $(\mathbf{B})$ treatment.

found in C: 22 patients had a higher cytology score, 16 lower and 15 had the same score.

\section{SNOT-22 test}

At T0, SNOT scores were similar in the two groups, but a trend towards a higher score was seen in G $(49.70 \pm 12.88$ for $\mathrm{G}$ and $44.08 \pm 17.49$ for $\mathrm{C} ; \mathrm{p}=0.06)$. At $\mathrm{T} 1 \mathrm{a}$ significant difference between the two groups was detected $(34.31 \pm 12.79$ for $\mathrm{G}$ and $43.81 \pm 17.16$ for $\mathrm{C} ; \mathrm{p}=0.0017)$ (Fig. 1C).

The Group x Factor interaction detected a significant difference of the variations at $\mathrm{T} 0$ and $\mathrm{T} 1$ between groups $(\mathrm{p}<0.001)$. A significant decrease $(\mathrm{p}<0.0001)$ in SNOT score at T0 and T1 was found in G. Only 1 subject had a higher SNOT score after treatment compared to 52 patients with a lower score; the large sample test statistic $\mathrm{Z}$ was 6.3164. No significant differences $(p=0.9881)$ in SNOT score at $\mathrm{T} 0$ and $\mathrm{T} 1$ were detected in $\mathrm{C}$ : in that group, 24 patients had a higher SNOT score, 25 patients lower and 4 had the same score. 
In our study, we obtained three new results from values $\mathrm{T} 0$ - values $\mathrm{T} 1$ for each variable: $\Delta$ vas $=1.38679 \pm 2.11377$, $\Delta$ cyto $=2.02830 \pm 5.92727, \Delta$ snot $=7.82075 \pm 9.42115$. Spearman's index improves the correlation model: the results were the same as Pearson's coefficient, and in fact there was a moderate correlation between $\Delta$ cytology and $\Delta$ vas $(\mathrm{r}=0.488 ; \mathrm{p}<0.0001)$, between $\Delta$ cytology and $\Delta$ snot $(\mathrm{r}=0.570 ; \mathrm{p}<0.0001)$ and, finally, between $\Delta \mathrm{vas}$ and $\Delta \mathrm{snot}$ $(\mathrm{r}=0.656 ; \mathrm{p}<0.0001)$.

The relations between the variables (cytology, VAS and SNOT) were presented in scatter plots with a regression line. (Figs. 3-5).

\section{Discussion}

Our study was designed to evaluate a liposomal based nasal spray containing vitamins $\mathrm{A}$ and $\mathrm{E}$, at the doses with the greatest potential for clinical use, in a large group of adult patients with allergic rhinitis who had rejected anti-allergic therapy for several reasons, mostly side effects such as drowsiness, dizziness and dry mouth.

Usually, pharmacological therapy of allergic rhinitis must take into account the severity and duration of symptoms, efficacy, availability, cost of the drugs and patient choices. The World Health Organization's guidelines on allergic rhinitis and its impact on asthma (ARIA) provide a progressive algorithm for treatment, recommending systemic or topical antihistamines or glucocorticoids with chromones as an alternative and then, if necessary, leukotriene antagonists and decongestants ${ }^{3}$. Unfortunately, both classic and new-generation antihistamines significantly

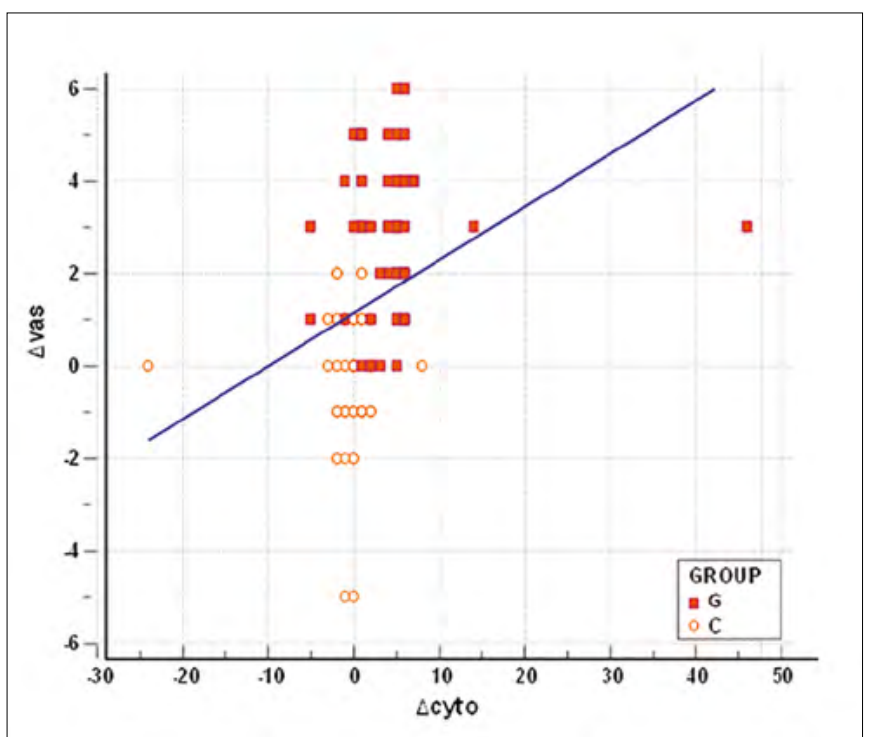

Figure 3. Regression between variations in cytology and variations in VAS.

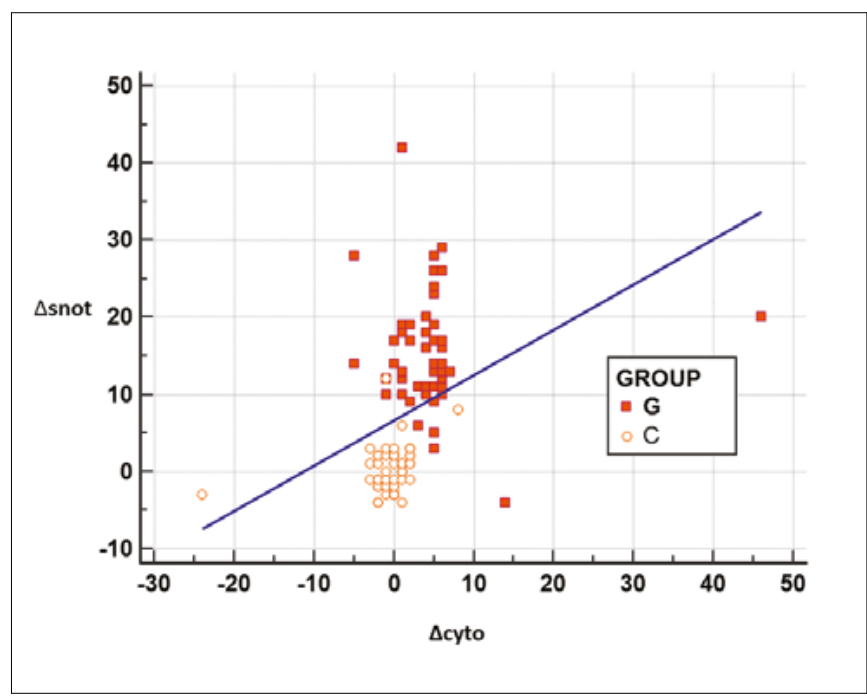

Figure 4. Regression between variations in cytology and SNOT.

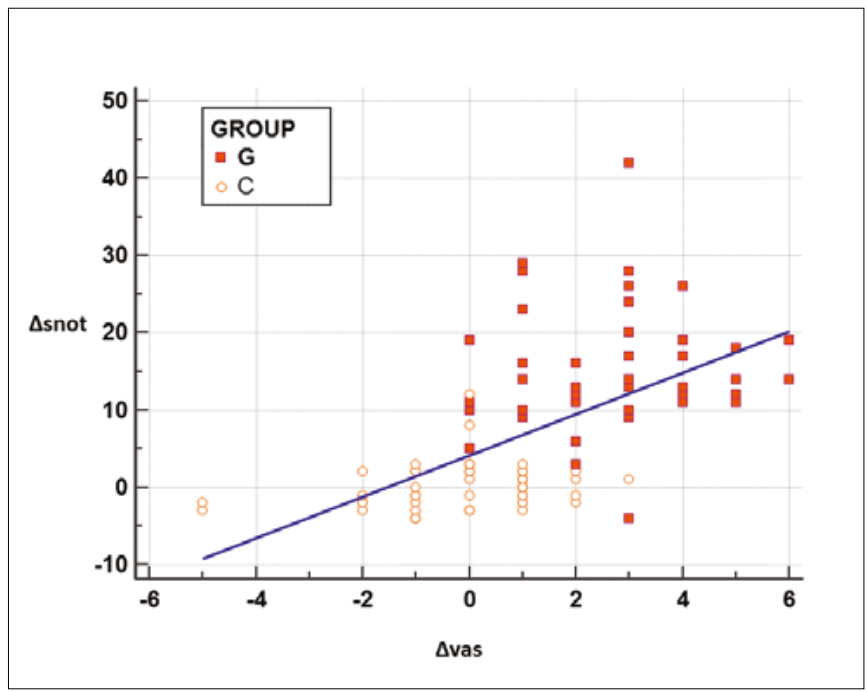

Figure 5. Regression between variations in VAS and SNOT.

increase daytime sleepiness and seem to have a negative influence on mood states ${ }^{10}$.

In the last few years, topical nasal corticosteroids have been established as first-line treatment for allergic rhinitis. However, nasal corticosteroids can produce hypothalamic-pituitary-adrenal axis suppression and other adverse effects. Fluticasone causes a reduction in endogenous cortisol secretion and there is little evidence that skeletal growth is restricted by the administration of topical nasal steroid sprays ${ }^{11}$. A high-dose and longterm nasal steroid administration may cause iatrogenic Cushing's syndrome that is characterised by complications of glucocorticoid excess, as well as serious and even lifethreatening complications of adrenal insufficiency ${ }^{12}$. Gross et al. demonstrated the efficacy and safety of a nasal spray 
composed by the association antihistamine-corticosteroid, which minimises the undesirable effects leaving the effectiveness of the active ingredients unaltered ${ }^{13}$.

A recent study analysed the montelukast effectiveness in improving oculonasal symptoms, patient-reported outcomes and eosinophilic biomarkers in responder patients: a significant reduction of eosinophils in nasal mucosa were observed after treatment ${ }^{14}$. Another study revealed significant vasodilation of human nasal mucosa after use of montelukast nasal spray in patients with allergic rhinitis, probably because of its $\alpha$-adrenoceptor antagonism ${ }^{15}$.

Chronic use of nasal decongestants is not recommended because their overuse can lead to rhinitis medicamentosa ${ }^{16}$. In our trial, we used a nasal spray composed of a solution of vitamin A, vitamin $\mathrm{E}$ and liposomes.

We used a liposomal nasal spray because liposomes, when applied in rhinitis, support the cleansing, lubrification and hydration of nasal mucosa. Liposomes consist of phospholipids that make up $75 \%$ of the protective nasal surfactant layer, so they are useful in treating mucosal barrier disorders that play an important role in the pathogenesis of allergic disease ${ }^{17}$. Liposomes are small sphere-shaped vesicles that can be created from cholesterol and natural phospholipids. An explanation for the mechanism of action of liposomes assumes that they stabilise the nasal mucosal barrier and treat its dysfunction by integrating in the damaged cell membrane protecting upper airways against pathogens ${ }^{18}$ thus stabilising respiratory barriers and strengthening their anti-inflammatory and wound-healing capacities ${ }^{19}$. Andersson et al. ${ }^{20}$ assumed that liposomes absorb and thus inactivate allergens. Liposomes are able to entrap proteins in the aqueous interior and have been widely used as drug delivery carriers due to their high biocompatibility ${ }^{21}$. Aliu et al. investigated the possibility of developing liposomes as a new allergen delivery system ${ }^{22}$ encapsulating allergens: it offers the ability to protect the allergen from degradation, potentially aids transport within tissues, and in turn targets APCs ${ }^{23}$. Several studies ${ }^{24-26}$ demonstrated that the symptoms of allergic rhinitis are effectively reduced by nasal application of liposomes, which have been available in the German pharmaceutical market since 2007, on inflamed nasal mucosa ${ }^{25}$. In the open, monocentric, prospective study by Weston et al. ${ }^{26}$, a liposomal nasal spray led to a significant reduction of AR symptoms of allergic rhinitis and improvement of QoL, comparable to the effect of a standard treatment with an antihistamine/glucocorticosteroid spray. The prescription-free liposomal based spray, as shown by Bohm et al. ${ }^{27}$ has an appreciable potential to reduce allergic rhinitis symptoms comparable to the established cromoglycate combination therapy, which is known to be evidence-based, albeit weakly effective allergy medication.
The nasal spray used in our study is also composed of vitamins $A$ and $E$ because of their important role in nasal mucosa: they are widely used in clinical practice for prevention and treatment of several medical conditions, especially in allergic symptoms.

Vitamin A has important effects on the immune response: low vitamin A (retinoic acid) levels are associated with less IFN- $\gamma$ and tendency for more viral detection, which may explain the association with vitamin A deficiency and rhinitis exacerbations. Indeed, IFN- $\gamma$ is a critical molecule in immune system with multiple functions, mostly related to Th1 response against bacterial, viral and fungal infections. Elenius et al. ${ }^{28}$ provided new evidence suggesting that vitamin A may have antiviral effects.

Vitamin E acts as an antioxidant in cellular membranes and scavenges free radicals by blocking the peroxidation of poly-unsaturated fatty acids. It also modifies prostaglandin formation and thereby enhances the production of prostaglandin I2, which inhibits the effects of histamine. In addition, the antioxidant role played by vitamin $\mathrm{E}$ reduces the level of immune inflammation. Zheng et al. ${ }^{29}$, using a model of induced nasal allergy in mice, demonstrated that a diet supplemented with high-dose vitamin $\mathrm{E}$ led to significant reduction in all the outwardly observable markers of nasal allergy compared with a diet supplemented with low-dose vitamin E. They demonstrated the improvement of symptom scores in patients with seasonal allergic rhinitis.

At the end of the present study, we observed, in group G, a significant improvement of nasal obstruction, evaluated by VAS, and a significant decrease in cell count analysed by nasal cytology, mostly neutrophils and eosinophils (Pearson coefficient $\mathrm{r}=0.323, \mathrm{p}=0.0007$; Spearman index $\mathrm{s}=0.488, \mathrm{p}<0.0001)$. The relationship between nasal obstruction and cytology has not been proposed in other studies. Gelardi et al. ${ }^{30}$ pointed out that allergic patients to pollens displayed higher levels of cellular infiltration (eosinophils, neutrophils and mast cells) and a greater increase in nasal resistance in comparison with perennial allergic patients. In our study, the scores recorded in the control group did not differ significantly comparing $\mathrm{T} 0$ and $\mathrm{T} 1$ data $(\mathrm{p}=0.845$ for VAS and $\mathrm{p}=0.189$ for cytology score in Wilcoxon rank sum test).

A significant improvement of QoL, evaluated by SNOT-22 test $(\mathrm{p}<0.0001)$, was detected after treatment in the study group. No significant differences in SNOT score were detected in the control group $(\mathrm{p}=0.9881)$.

These significant and innovative results are a valid answer to the question about the efficacy of the proposed nasal spray as a complementary rather than alternative therapy in patients suffering from persistent allergic rhinitis. 


\section{Conclusions}

In conclusion, our study provides evidence that this liposomal nasal spray is able to improve nasal symptoms of $\mathrm{AR}$, and thus significant improvement of QoL. Patients were compliant with this therapy because of minor side effects compared with anti-allergic therapy. The effectiveness of this liposomal nasal spray in terms of reduction of inflammatory cell counts is remarkable. It confirms the close association between inflammatory cell count and nasal obstruction. These results may have implications for clinical practice, and in fact the use of liposomal nasal spray with vitamins $\mathrm{A}$ and $\mathrm{E}$ can be considered a complementary therapy in patients suffering from persistent allergic rhinitis. Our findings highlight the importance of this liposomal nasal spray in improving nasal symptoms and local inflammation, but further experimental studies are needed to better define the mechanisms.

\section{References}

1 Small P, Frenkiel S, Becker A, et al. Rhinitis: a practical and comprehensive approach to assessment and therapy. J Otolaryngol 2007;36(Suppl 1):S5-27.

2 Zuberbier T, Lotvall J, Simoens S, et al. Economic burden of inadequate management of allergic diseases in the European Union: a GA(2) LEN review. Allergy 2014;69:1275-9. https://doi.org/10.1111/all.12470

3 Brożek JL, Bousquet J, Agache I, et al. Allergic Rhinitis and its Impact on Asthma (ARIA) guidelines - 2016 revision. J Allergy Clin Immunol 2017;140:950-8. https://doi.org/10.1016/j.jaci.2017.03.050

4 Mozzanica F, Preti A, Gera R, et al. Cross-cultural adaptation and validation of the SNOT-22 into Italian. Eur Arch Otorhinolaryngol 2017;274:887-95. https://doi.org/10.1007/s00405-016-4313-x

5 Rosati MG, Peters AT. Relationships among allergic rhinitis, asthma, and chronic rhinosinusitis. Am J Rhinol Allergy 2016;30:44-7. https:// doi.org/10.2500/ajra.2016.30.4252

6 Hopkins C, Gillett S, Slack R, et al. Psychometric validity of the 22-item sinonasal outcome test. Clin Otolaryngol 2009;34:447-54. https://doi.org/10.1111/j.1749-4486.2009.01995.x

7 Bousquet PJ, Combescure C, Neukirch F, et al. Visual analog scales can assess the severity of rhinitis graded according to ARIA guidelines. Allergy 2007;62:367-72. https://doi.org/10.1111/j.13989995.2006.01276.x

8 Doulaptsi M, Prokopakis E, Seys S, et al. Visual analogue scale for sino-nasal symptoms severity correlates with sino-nasal outcome test 22: paving the way for a simple outcome tool of CRS burden. Clin Transl Allergy 2018;8:32. https://doi.org/10.1186/s13601-018-0219-6

9 Gelardi M, Iannuzzi L, Quaranta N, et al. NASAL cytology: practical aspects and clinical relevance. Clin Exp Allergy 2016;46:785-92. https://doi.org/10.1111/cea.12730

10 Ozdemir PG, Karadag AS, Selvi Y, et al. Assessment of the effects of antihistamine drugs on mood, sleep quality, sleepiness, and dream anxiety. Int J Psychiatry Clin Pract 2014;18:161-8. https://doi.org/10. 3109/13651501.2014.907919

11 Waddell AN, Patel SK, Toma AG, et al. Intranasal steroid sprays in the treatment of rhinitis: is one better than another? J Laryngol Otol 2003;117:843-5. https://doi.org/10.1258/002221503322542818

12 Dursun F, Kirmizibekmez H. Iatrogenic Cushing's syndrome caused by intranasal steroid use. North Clin Istanb 2016;4:97-9. https://doi. org/10.14744/nci.2016.38981

13 Gross GN, Berman G, Amar NJ, et al. Efficacy and safety of olopatadine-mometasone combination nasal spray for the treatment of seasonal allergic rhinitis. Ann Allergy Asthma Immunol 2019;122:630-8. e3. https://doi.org/10.1016/j.anai.2019.03.017

14 De Corso E, Anzivino R, Galli J, et al. Antileukotrienes improve nasoocular symptoms and biomarkers in patients with NARES and asthma. Laryngoscope 2019;129:551-7. https://doi.org/10.1002/lary.27576

15 Wang HW, Lee JC, Wu PC, et al. Effects of montelukast on human nasal mucosa. Eur Arch Otorhinolaryngol 2019;276:761-5. https:// doi.org/10.1007/s00405-018-05274-8

16 Wang YN, Luan ZL, Wang HT. Research progress on rhinitis medicamentosa.ZhonghuaErBiYan Hou Tou Jing Wai KeZaZhi 2017;52:8725. https://doi.org/10.3760/cma.j.issn.1673-0860.2017.11.019

17 Yarosh D. Topical application of liposomes. J Photochem Photobiol B 1990;6:445-9. https://doi.org/10.1007/978-3-642-48391-2_27

18 Homann H, Rosbach O, Moll W, et al. A liposome hydrogel with polyvinyl-pyrrolidone iodine in the local treatment of partial-thickness burn wounds. Ann Plast Surg 2007;59:423-7. https://doi.org/10.1097/ SAP.0b013e3180326fcf

19 Kanmaz T, Karakayali H, Sakallioglu A, et al. Polyunsaturated phosphatidylcholine protects against wound contraction in experimental skin burn injury. J Invest Surg 2004;17:15-22.

20 Andersson M, Greiff L, Ojeda P, et al. Barrier-enforcing measures as treatment principle in allergic rhinitis: a systematic review. Curr Med Res Opin 2014;30:1131-7. https://doi.org/ 10.1185/03007995.2014.882299

21 Gregoriadis G, McCormack B, Obrenovic M, et al. Vaccine entrapment in liposomes. Methods 1999;19:156-62. https://doi.org/10.1006/ meth.1999.0841

22 Aliu H, Rask C, Brimnes J, et al. Enhanced efficacy of sublingual immunotherapy by liposome-mediated delivery of allergen. Int $\mathrm{J} \mathrm{Na}$ nomedicine 2017;12:8377-88. https://doi.org/10.2147/IJN.S137033

23 Klippstein R, Pozo D. Nanotechnology-based manipulation of dendritic cells for enhanced immunotherapy strategies. Nanomedicine 2010;6:523-9. https://doi.org/10.1016/j.nano.2010.01.001

24 Andersson M, Greiff L, Wollmer P. Nasal treatment with a microemulsion reduces allergen challenge-induced symptoms and signs of allergic rhinitis. Acta Otolaryngol 2008;128:666-9. https://doi. org/10.1080/00016480701642197

25 Eitenmüller A, Piano L, Böhm M, et al. Liposomal nasal spray versus guideline-recommended steroid nasal spray in patients with chronic rhinosinusitis: a comparison of tolerability and quality of life. J Allergy (Cairo) 2014;2014:146280. https://doi.org/10.1155/2014/146280

26 Weston LA, Mösges R. Treating seasonal allergic rhinoconjunctivitis with a liposomal nasal spray. Allergologie 2010;33:196-204. https:// doi.org/10.1007/s00405-011-1696-6

27 Böhm M, Avgitidou G, El Hassan E, et al. Liposomes: a new nonpharmacological therapy concept for seasonal-allergic-rhinoconjunctivitis. Eur Arch Otorhinolaryngol 2012;269:495-502. https://doi. org/10.1007/s00405-011-1696-6

28 Elenius V, Palomares O, Waris M, et al. The relationship of serum vitamins A, D, E and LL-37 levels with allergic status, tonsillar virus detection and immune response. PLoS One 2017;12:e172350. https://doi.org/10.1371/journal.pone.0172350

29 A Zheng K-C, Adjei AA, Shinjo M, et al. Effect of dietary vitamin E supplementation on murine nasal allergy. Am J Med Sci 1999;318:49-54. https://doi.org/10.1097/00000441-199907000-00008

30 Gelardi M, Maselli Del Giudice A, Candreva T, et al. Nasal resistance and allergic inflammation depend on allergen type. Int Arch Allergy Immunol 2006;141:384-9. https://doi.org/10.1159/000095465 